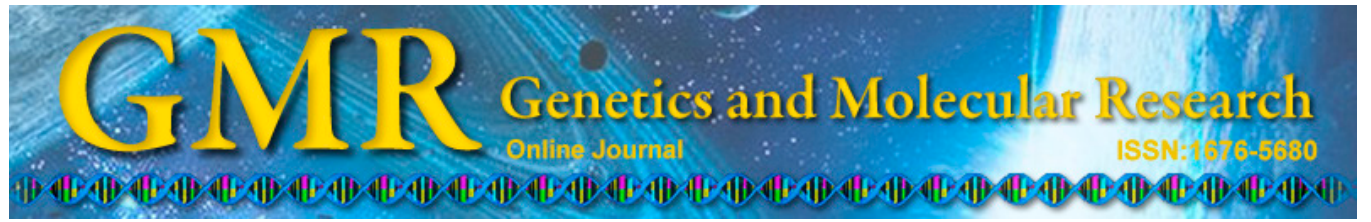

\title{
Angiotensin-converting enzyme insertion/ deletion polymorphism and susceptibility to systemic sclerosis: a meta-analysis
}

\author{
G.G. Song and Y.H. Lee \\ Division of Rheumatology, Department of Internal Medicine, \\ Korea University College of Medicine, Seoul, Korea \\ Corresponding author: Y.H. Lee \\ E-mail: lyhcgh@korea.ac.kr \\ Genet. Mol. Res. 13 (4): 8174-8183 (2014) \\ Received September 16, 2013 \\ Accepted December 12, 2013 \\ Published October 7, 2014 \\ DOI http://dx.doi.org/10.4238/2014.October.7.12
}

\begin{abstract}
The purpose of this study was to examine whether the insertion (I) or deletion (D) polymorphism of the angiotensin-converting enzyme gene $(A C E)$ is associated with susceptibility to systemic sclerosis (SSc). A meta-analysis examining the associations between the $A C E \mathrm{I} / \mathrm{D}$ polymorphism and $\mathrm{SSc}$ was conducted in overall and European populations using 1) allelic contrast (D vs I); 2) recessive (DD vs ID + II); 3) dominant (DD + ID vs II); and 4) additive (DD vs ID vs II) models. A total of 7 studies consisting of 837 cases and 754 controls were available for meta-analysis. The meta-analysis revealed no association between the D allele and $\mathrm{SSc}$ in any study subjects [odds ratio $(\mathrm{OR})=0.956$, $95 \%$ confidence interval $(\mathrm{CI})=0.733-1.246, \mathrm{P}=0.737]$. Stratification by ethnicity indicated no association between the $\mathrm{D}$ allele of the $A C E$ $\mathrm{I} / \mathrm{D}$ polymorphism and SSc in Europeans $(\mathrm{OR}=1.117,95 \% \mathrm{CI}=0.776-$ $1.607, \mathrm{P}=0.551$ ). Meta-analysis using all other genetic models showed the same $\mathrm{D}$ allele pattern in the overall and European groups. This metaanalysis showed that the $A C E \mathrm{I} / \mathrm{D}$ polymorphism was not associated with susceptibility to SSc in the study subjects and in Europeans.
\end{abstract}

Key words: Angiotensin-converting enzyme; Meta-analysis; Polymorphism; Systemic sclerosis; Association 


\section{INTRODUCTION}

Systemic sclerosis ( $\mathrm{SSc}$ ) is a multisystem, inflammatory, autoimmune disease characterized by progressive fibrosis of the skin and internal organs (Gabrielli et al., 2009). Overproduction and accumulation of collagen in the skin and viscera are the major pathological features of SSc, and microvascular involvement by endothelial derangement impairs organ blood flow. SSc is a complex disease that occurs in genetically predisposed individuals who are exposed to environmental risk factors.

Angiotensin-converting enzyme (ACE) converts angiotensin I into angiotensin II and inactivates bradykinin via the kallikrein-kininogen system (Coates, 2003; Bryant and Shariat-Madar, 2009). Angiotensin II, a potent vasoconstrictor, is the main effector molecule of the renin-angiotensin-system (RAS). The RAS contributes to electrolyte homeostasis and regulates blood pressure in vivo (Coates, 2003). Dysregulation of this system can contribute to the development of essential hypertension. Furthermore, angiotensin II is a potent proinflammatory modulator that augments immune responses (Kranzhofer et al., 1999; Nataraj et al., 1999; Marchesi et al., 2008; Bryant and Shariat-Madar, 2009). The $A C E$ gene, located on chromosome 17q23, contains an insertion (I)/deletion (D) polymorphism within intron 16 that may contain or lack a 250-287 base pair (bp) repeat sequence (Rigat et al., 1990). The DD genotype is associated with an approximately 2-fold higher tissue (Costerousse et al., 1993; Danser et al., 1995) and plasma concentration of ACE than the II genotype (Rigat et al., 1990). Thus, the D allele may play a role in the pathogenesis of SSc.

The $A C E \mathrm{I} / \mathrm{D}$ polymorphism has been examined in the context of SSc. However, published results regarding the genetic associations of the $A C E \mathrm{I} / \mathrm{D}$ polymorphism are controversial and inconclusive. This may be because of small sample sizes, low statistical power, and/or clinical heterogeneity (Fatini et al., 2002; Assassi et al., 2005; Guiducci et al., 2006; Joung et al., 2006; Wipff et al., 2009). To overcome the limitations of individual studies, resolve inconsistencies, and reduce the likelihood that random errors were responsible for false-positive or false-negative associations (Nath et al., 2005; Lee et al., 2005, 2006), we conducted a meta-analysis to further characterize the association and to investigate whether the $A C E \mathrm{I} / \mathrm{D}$ polymorphism contributes to SSc susceptibility.

\section{MATERIAL AND METHODS}

\section{Identification of eligible studies and data extraction}

A literature search for studies that examined the association between the $A C E \mathrm{I} / \mathrm{D}$ polymorphism and SSc was conducted. The MEDLINE and EMBASE citation indices were used to identify articles published up to June 2013 in which the $A C E$ I/D polymorphism was identified in SSc patients and controls. In addition, all references in the articles identified were reviewed to identify studies not indexed by MEDLINE and EMBASE. The following key words and subject terms were used in the search: "angiotensin-converting enzyme", "ACE", "systemic sclerosis", and "SSc". Studies were included in the analysis if they: 1) were case-controlled, 2) contained original data, and 3) included sufficient data to calculate odds ratios (ORs). No language restriction was applied. We excluded studies: 1) with overlapping data; 2) in which the number of null and wild-type genotypes or alleles could not be 
ascertained; 3) in which family members were studied because their analysis was based on linkage considerations; and 4) in which the genotype distribution in controls was not consistent with Hardy-Weinberg equilibrium (HWE), because deviation from HWE among controls suggests bias during control selection or genotyping errors. Data were extracted from the original studies by 2 independent reviewers. Any discrepancies between the reviewers were resolved by consensus or by a third reviewer. The following information was extracted from each study identified: author, year of publication, ethnicity of the study population, demographics, numbers of cases and controls, and the genotype and allele frequencies of the $A C E$ I/D polymorphism.

\section{Evaluation of publication bias and study quality}

The chi-square test was used to determine whether the observed genotype frequencies in controls conformed to HWE expectations. Funnel plots are often used to detect publication bias, but they require a range of studies of varying sizes and subjective judgments; therefore, we evaluated publication bias using Egger's linear regression test (Egger et al., 1997a). Egger's linear regression test measures funnel plot asymmetry on a natural logarithmic scale of ORs.

\section{Evaluation of statistical associations}

We performed meta-analyses using 1) allelic contrast (D vs I);2) recessive (DD $v s$ ID + II); 3) dominant (DD + ID vs II); and 4) additive (DD $v s$ ID $v s$ II) models. Point estimates of risks, ORs, and 95\% confidence intervals (CIs) were calculated for each study. In addition, within- and between-study variations and heterogeneities were assessed using Cochran's $Q$-statistic test. Cochran's $Q$-statistic test assesses the null hypothesis that all studies evaluated the same effect. The effect of heterogeneity was quantified using the $I^{2}$ value with the range of $0-100 \%$, representing the proportion of between-study variability attributable to heterogeneity rather than to chance (Higgins and Thompson, 2002). $I^{2}$ values of 25,50 , and $75 \%$ were nominally assigned as low, moderate, and high estimates. The fixed effects model assumes that a genetic factor has a similar effect on disease susceptibility across all studies investigated, and that observed variations among studies are caused by chance alone (Egger et al., 1997b). The random effects model assumes that different studies show substantial diversity and assesses both within-study sampling error and betweenstudy variance (DerSimonian and Laird, 1986). When study groups are homogeneous, the 2 models are similar. If a study group lacks homogeneity, a random effects model typically provides wider CIs than the fixed effects model. The random effects model is the most appropriate when significant between-study heterogeneity exists (DerSimonian and Laird, 1986). Statistical manipulations were conducted using the Comprehensive Meta-Analysis computer program (Biosta; Englewood, NJ, USA). The power of each study was computed as the probability of detecting an association between the $A C E$ polymorphism and SSc using a significance level of 0.05 and assuming a small effect size. Power analysis was performed using the statistical program G*Power (http://www.psycho.uni-duesseldorf.de/ aap/projects/gpower). 


\section{RESULTS}

\section{Studies included in the meta-analysis}

Nineteen studies were identified by electronic and manual searches, 6 of which were selected for full-text review based on title and abstract details (Fatini et al., 2002; Assassi et al., 2005; Guiducci et al., 2006; Joung et al., 2006; Bartoli et al., 2007; Wipff et al., 2009). One study was excluded because it contained duplicate data for the $A C E$ I/D polymorphism (Bartoli et al., 2007). Thus, a total of 5 articles met our inclusion criteria. One eligible study contained data on 3 different SSc groups (Assassi et al., 2005) that were treated independently. Thus, a total of 7 separate comparisons met our inclusion criteria (Figure 1). These consisted of 4 European studies and one study each in Asian, African American, and Latin American populations comprising a total of 837 cases and 754 controls. Selected details of the individual studies are summarized in Table 1. The statistical power of these 7 studies ranged from 11.6 to $79.4 \%$. None of the studies had statistical power exceeding $80 \%$.

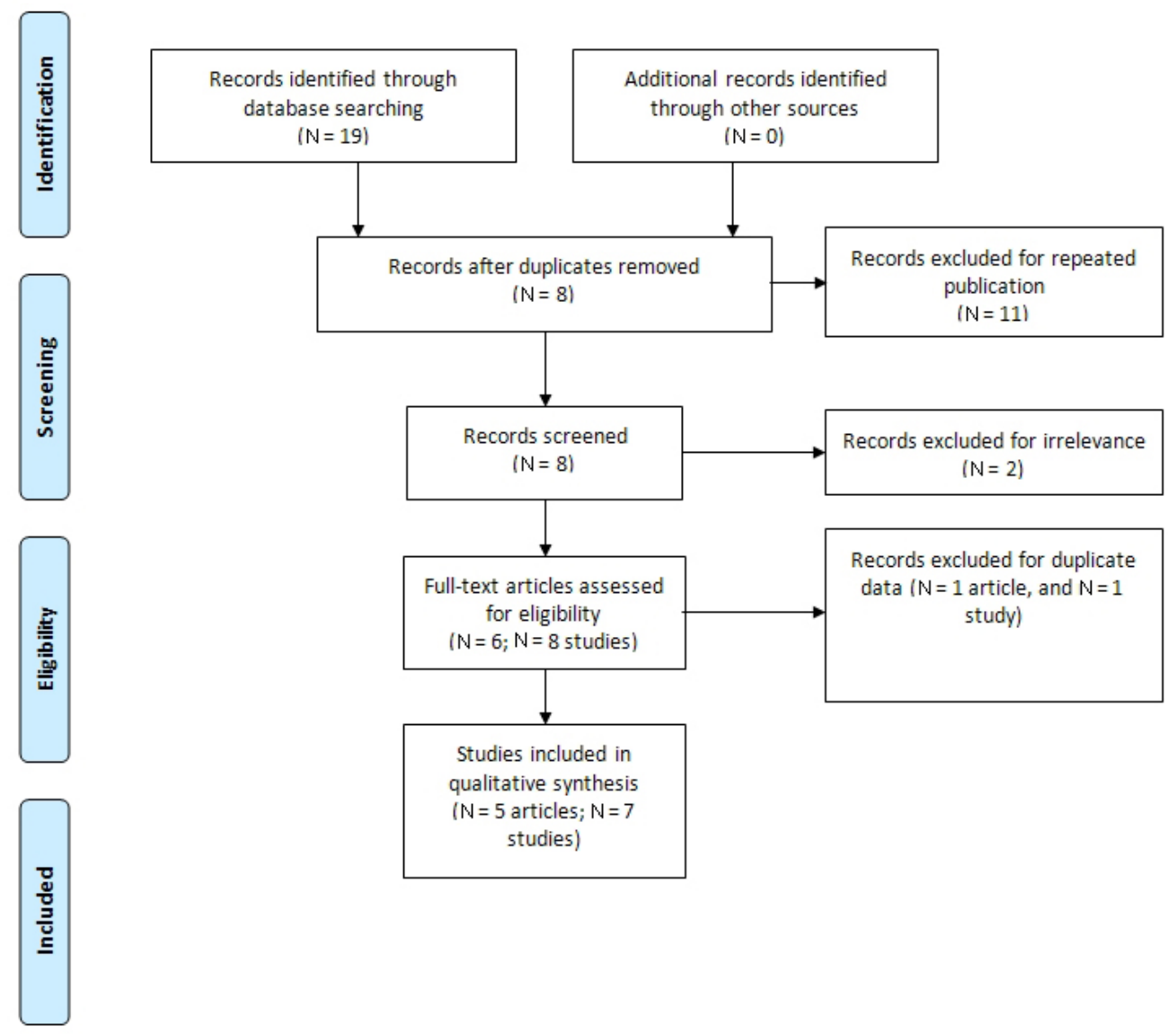

Figure 1. Study flow chart. 
G.G. Song and Y.H. Lee

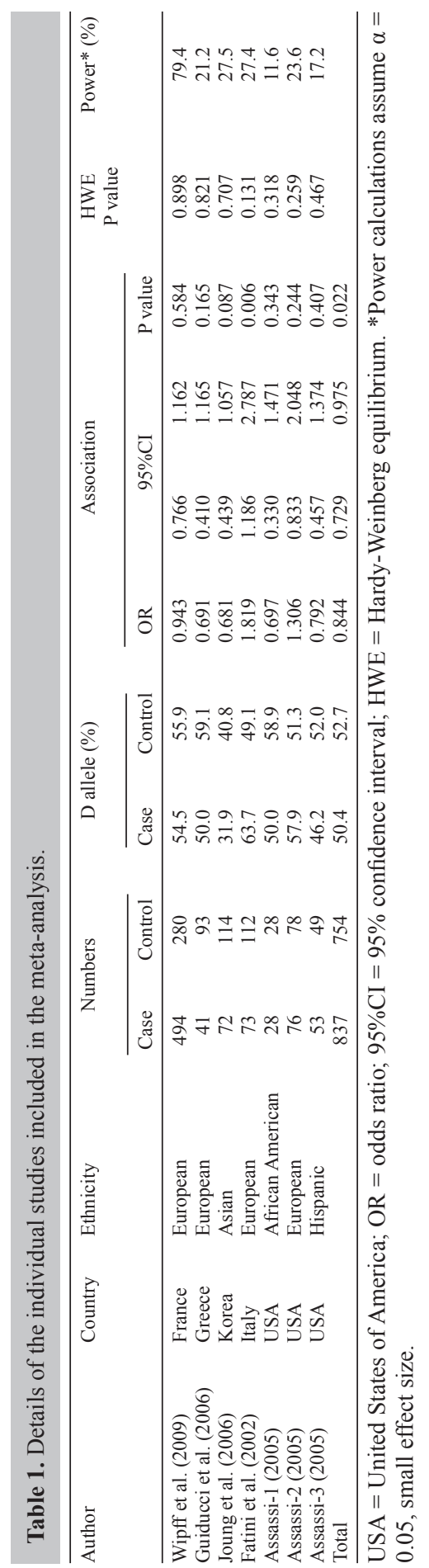




\section{Frequencies of the $\mathrm{D}$ allele of the $A C E \mathrm{I} / \mathrm{D}$ polymorphism in different ethnic groups}

The mean frequency of the $\mathrm{D}$ allele of the $A C E \mathrm{I} / \mathrm{D}$ polymorphism was $52.7 \%$ among all normal controls, with Asians showing a lower D allele prevalence than the other ethnic groups (40.8\%). Among normal controls, the frequencies of the $\mathrm{D}$ allele in the Asian, Latin American, European, and African-American populations were 40.8, 52.0, 54.4, and 58.9\%, respectively (Table 2).

Table 2. Prevalence of the D allele of the $A C E$ I/D polymorphism.
\begin{tabular}{lcrcrcr}
\hline Population & No. of studies & \multicolumn{2}{c}{ Numbers } & & \multicolumn{2}{c}{ D allele (\%) } \\
\cline { 2 - 6 } & & Case & Control & & Case & Control \\
\hline European & 4 & 684 & 563 & 55.6 & 54.4 \\
Asian & 1 & 72 & 114 & 31.9 & 40.8 \\
African American & 1 & 28 & 28 & 50.0 & 58.9 \\
Hispanic & 1 & 53 & 49 & 46.2 & 52.0 \\
Overall & 7 & 837 & 754 & 52.4 & 52.7 \\
\hline
\end{tabular}

\section{Meta-analysis of the association between the $A C E$ I/D polymorphism and SSc}

A meta-analysis of all SSc patients and of each ethnic group was conducted. A summary of the findings regarding the relationship between the $A C E \mathrm{I} / \mathrm{D}$ polymorphism and SSc is shown in Table 3. Meta-analysis revealed no association between the D allele and SSc in all study subjects $(\mathrm{OR}=0.956,95 \% \mathrm{CI}=0.733-1.246, \mathrm{P}=0.737)$ (Table 3 , Figure 2$)$. Stratification by ethnicity indicated no association between the $\mathrm{D}$ allele of the $A C E \mathrm{I} / \mathrm{D}$ polymorphism and SSc in Europeans $(\mathrm{OR}=1.117,95 \% \mathrm{CI}=0.776-1.607, \mathrm{P}=0.551)$ (Table 3, Figure 2). Meta-analysis using all other genetic models showed the same D allele pattern in the overall group and in Europeans, suggesting no association between the $A C E \mathrm{I} / \mathrm{D}$ polymorphism and SSc risk (Table 3).

\begin{tabular}{|c|c|c|c|c|c|c|c|}
\hline \multirow[t]{2}{*}{ Study name } & \multicolumn{4}{|c|}{ Statistics for each study } & \multicolumn{3}{|c|}{ Odds ratio and $95 \% \mathrm{Cl}$} \\
\hline & $\begin{array}{l}\text { Odds } \\
\text { ratio }\end{array}$ & $\begin{array}{l}\text { Lower } \\
\text { limit }\end{array}$ & $\begin{array}{c}\text { Upper } \\
\text { limit }\end{array}$ & $P$ value & & & \\
\hline Wipff et al., 2009 & 0.943 & 0.766 & 1.162 & 0.584 & & & \\
\hline Guiducci et al., 2006 & 0.691 & 0.410 & 1.165 & 0.165 & & & \\
\hline Joung et al., 2006 & 0.681 & 0.439 & 1.057 & 0.087 & & & \\
\hline Fatini et al., 2002 & 1.819 & 1.186 & 2.787 & 0.006 & & & \\
\hline Assassi-1, 2005 & 0.697 & 0.330 & 1.471 & 0.343 & & & \\
\hline Assassi-2, 2005 & 1.306 & 0.833 & 2.048 & 0.244 & & & \\
\hline \multirow[t]{3}{*}{ Assassi-3, 2005} & 0.792 & 0.457 & 1.374 & 0.407 & & & \\
\hline & 0.956 & 0.733 & 1.246 & 0.737 & & & \\
\hline & & & & & 0.10 .2 & 0.51 & 5 \\
\hline
\end{tabular}

Figure 2. Odds ratios (ORs) and 95\% confidence intervals (CIs) of individual studies and pooled data for the association between the $\mathrm{D}$ allele of the $A C E \mathrm{I} / \mathrm{D}$ polymorphism and systemic sclerosis in all study subjects and in each ethnic group. 
Table 3. Meta-analysis of the association between the $A C E$ I/D polymorphism and systemic sclerosis.

\begin{tabular}{|c|c|c|c|c|c|c|c|c|}
\hline \multirow[t]{2}{*}{ Polymorphism } & \multirow[t]{2}{*}{ Population } & \multirow[t]{2}{*}{ No. of studies } & \multicolumn{3}{|c|}{ Test of association } & \multicolumn{3}{|c|}{ Test of heterogeneity } \\
\hline & & & OR & $95 \% \mathrm{CI}$ & $P$ value & Model & $P$ value & $I^{2}$ \\
\hline \multirow{2}{*}{$\mathrm{D} v s$ I allele } & Overall & 7 & 0.956 & $0.733-1.246$ & 0.737 & $\mathrm{R}$ & 0.017 & 61.1 \\
\hline & European & 4 & 1.117 & $0.776-1.607$ & 0.551 & $\mathrm{R}$ & 0.013 & 72.0 \\
\hline \multirow{2}{*}{$\begin{array}{l}\text { DD+ID vs II } \\
\text { (Dominant) }\end{array}$} & & & & & & & & \\
\hline & $\begin{array}{l}\text { Overall } \\
\text { European }\end{array}$ & $\begin{array}{l}7 \\
4\end{array}$ & $\begin{array}{l}1.124 \\
1.384\end{array}$ & $\begin{array}{l}0.703-1.796 \\
0.682-2.807\end{array}$ & $\begin{array}{l}0.625 \\
0.368\end{array}$ & $\begin{array}{l}R \\
R\end{array}$ & $\begin{array}{l}0.012 \\
0.006\end{array}$ & $\begin{array}{l}63.3 \\
75.5\end{array}$ \\
\hline \multirow[t]{2}{*}{$\begin{array}{l}\text { DD } v s \text { ID+II } \\
\text { (Recessive) }\end{array}$} & Overall & 7 & 0.899 & $0.714-1.132$ & 0.363 & F & 0.153 & 36.1 \\
\hline & European & 4 & 0.995 & $0.775-1.278$ & 0.970 & $\mathrm{~F}$ & 0.283 & 21.2 \\
\hline \multirow{2}{*}{ DD $v s$ II } & Overall & 7 & 0.947 & $0.538-1.668$ & 0.851 & $\mathrm{R}$ & 0.017 & 61.1 \\
\hline & European & 4 & 1.301 & $0.595-2.842$ & 0.510 & $\mathrm{R}$ & 0.010 & 73.7 \\
\hline \multirow[t]{2}{*}{ DD $v s$ ID } & Overall & 7 & 0.855 & $0.670-1.091$ & 0.207 & $\mathrm{~F}$ & 0.385 & 5.53 \\
\hline & European & 4 & 0.935 & $0.717-1.219$ & 0.618 & $\mathrm{~F}$ & 0.781 & 0 \\
\hline \multirow[t]{2}{*}{ ID $v s$ II } & Overall & 7 & 1.219 & $0.768-1.934$ & 0.401 & $\mathrm{R}$ & 0.026 & 58.0 \\
\hline & European & 4 & 1.429 & $0.728-2.805$ & 0.299 & $\mathrm{R}$ & 0.019 & 69.9 \\
\hline
\end{tabular}

$A C E \mathrm{I} / \mathrm{D}=$ angiotensin-converting enzyme insertion and deletion; $\mathrm{OR}=$ odds ratio; $95 \% \mathrm{CI}=95 \%$ confidence interval; $\mathrm{F}=$ fixed effects model; $\mathrm{R}$ = random effects model.

\section{Heterogeneity and publication bias}

In the meta-analyses, we observed between-study heterogeneity for the allele contrast, dominant model, homozygote contrast, and ID vs II contrast in all study subjects and in Europeans (Table 3). However, heterogeneity was not found in the meta-analyses using the recessive model and the DD vs ID contrast in the overall group and in Europeans (Table 3). Publication bias causes a disproportionate number of positive studies and poses a problem for meta-analyses. However, evidence of publication bias was not found in these meta-analyses of the $A C E \mathrm{I} / \mathrm{D}$ polymorphism (Egger's regression test $\mathrm{P}$ values $>0.1$ ) (Figure 3).

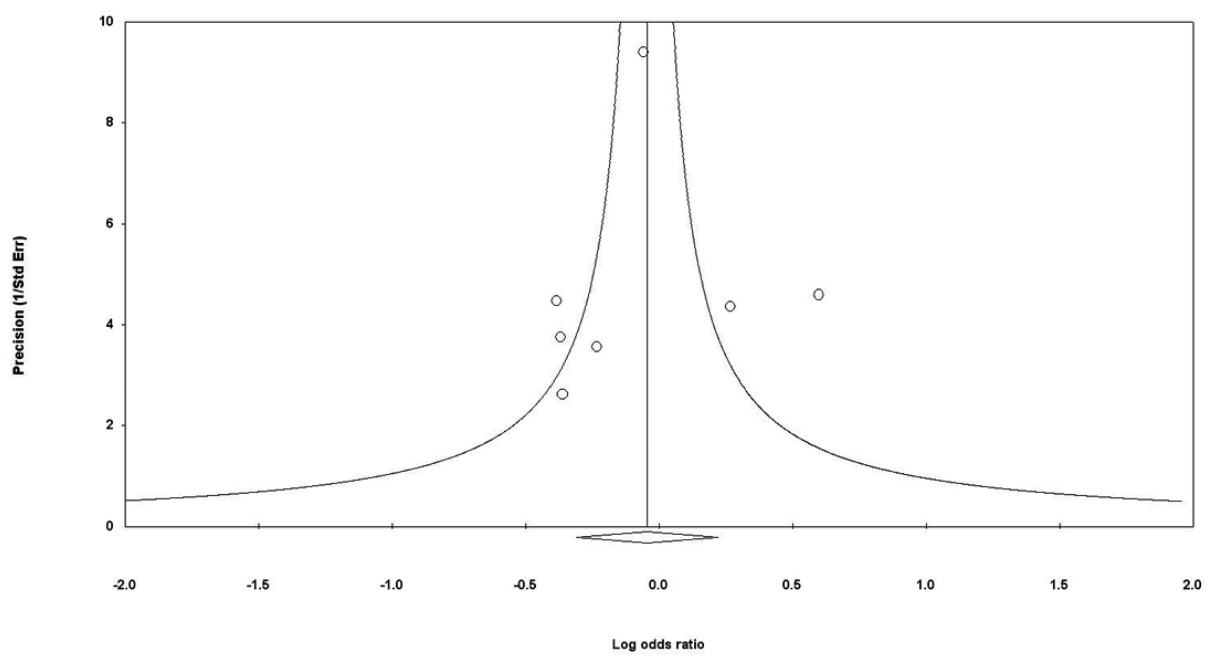

Figure 3. Funnel plot of studies on the associations between the $\mathrm{D}$ allele of the $A C E \mathrm{I} / \mathrm{D}$ polymorphism and systemic sclerosis in all subjects (Egger's regression P value $=0.805$ ). 


\section{DISCUSSION}

ACE is expressed in a wide range of tissues, including the kidneys, heart, lungs, vascular endothelium, skin, joints, and testes (Costerousse et al., 1993; Danser et al., 1995). ACE plays an important role in RAS and angiotensin II conversion, directly increases vascular smooth muscle cell contraction, and affects smooth muscle proliferation, monocyte adhesion, platelet adhesion, and aggregation (Coates, 2003; Bryant and Shariat-Madar, 2009). The $A C E$ I/D polymorphism accounts for $47 \%$ of the variation in ACE plasma activity (Rigat et al., 1990); therefore, the source of most variation remains unknown.

This polymorphism has been studied in connection with several diseases, including Alzheimer's disease (Belbin et al., 2011), myocardial infarction (Samani et al., 1996), cerebral infarction (Tao et al., 2009), hypertension (Li, 2012), and vasculitis (Lee et al., 2012). These studies reported associations between susceptibilities to these diseases and the DD genotype and D allele (Samani et al., 1996; Tao et al., 2009; Belbin et al., 2011; Lee et al., 2012; Li, 2012). Activation of RAS during renal crisis in SSc patients and the dramatically improved outcome of renal crisis in SSc produced by ACE inhibitors (Steen et al., 1990) suggest that $A C E$ is a candidate gene for SSc.

In this meta-analysis, we combined information regarding the association between the $A C E \mathrm{I} / \mathrm{D}$ polymorphism and susceptibility to SSc. The meta-analysis revealed no association between the $A C E \mathrm{I} / \mathrm{D}$ polymorphism and SSc in any study subjects. In addition, stratification by ethnicity indicated no association between the $\mathrm{D}$ allele of the $A C E \mathrm{I} / \mathrm{D}$ polymorphism and SSc in Europeans, with a high heterogeneity.

The results of our study should be interpreted with caution. Our meta-analysis failed to reveal an association between the $A C E \mathrm{I} / \mathrm{D}$ polymorphism and susceptibility to $\mathrm{SSc}$, which conflicts with the results of functional studies conducted on the $A C E$ I/D polymorphism (Costerousse et al., 1993; Danser et al., 1995). It is not uncommon that epidemiologic results fail to concur with the results of functional studies. In the present study, this may be attributed to the complexity of SSc, as multiple genes, different genetic backgrounds, and various environmental factors contribute to its development. In contrast, because a relatively small number of studies with low statistical power were included in our meta-analysis, our results are likely due to a Type II error (false negative). Between-study heterogeneity was found in this metaanalysis in the overall patient group. Heterogeneity was also found in the homogeneous ethnic group of Europeans. A significant difference in the $A C E \mathrm{D}$ allele frequency was observed between Italian and Greek healthy subjects, and an association was found between the $A C E \mathrm{D}$ allele and SSc in Italians, but not in Greeks. The reason for the heterogeneity is unclear, but this heterogeneity may have affected the results of meta-analysis. Thus, our findings suggest that further investigations are required before the nature of the association between the $A C E$ I/D polymorphism and susceptibility to SSc can be accurately determined.

There were some limitations to the present study. First, publication bias and confounding factors may have distorted the analysis. Second, other $A C E$ polymorphisms capable of affecting ACE activity may also be associated with SSc. However, the limited amount of data available prevented further meta-analysis. Third, it would have been interesting to examine the associations between the $A C E$ I/D polymorphism and disease activities and clinical features and to have stratified the data by gender or autoantibody status, but such studies could not be performed because of limited or unavailable data. Fourth, we included data from Euro- 
pean, Asian, African American, and Hispanic patients in our meta-analysis, but our ethnicityassociated results are applicable only to European ethnic groups. European populations demonstrated a higher frequency of the D allele (54.4\%), while Asians showed a lower frequency of the D allele (40.8\%). Further studies are needed in specific ethnic groups.

In conclusion, this meta-analysis of the $A C E \mathrm{I} / \mathrm{D}$ polymorphism, which was based on a total sample of 837 patients and 754 controls, demonstrated no association between the $A C E \mathrm{I} / \mathrm{D}$ polymorphism and SSc in any study subjects and in Europeans. Larger-scale studies in homogeneous populations from various ethnicities are needed to explore the relationships between polymorphisms of the $A C E$ gene and the pathogenesis of SSc.

\section{Conflicts of interest}

The authors declare no conflict of interest.

\section{REFERENCES}

Assassi S, Mayes MD, McNearney T, Fischbach M (2005). Polymorphisms of endothelial nitric oxide synthase and angiotensin-converting enzyme in systemic sclerosis. Am. J. Med. 118: 911.

Bartoli F, Angotti C, Fatini C, Conforti ML, et al. (2007). Angiotensin-converting enzyme I/D polymorphism and macrovascular disease in systemic sclerosis. Rheumatology 46: 772-775.

Belbin O, Brown K, Shi H, Medway C, et al. (2011). A multi-center study of ACE and the risk of late-onset Alzheimer's disease. J. Alzheimers. Dis. 24: 587-597.

Bryant JW and Shariat-Madar Z (2009). Human plasma kallikrein-kinin system: physiological and biochemical parameters. Cardiovasc. Hematol. Agents Med. Chem. 7: 234-250.

Coates D (2003). The angiotensin converting enzyme (ACE). Int. J. Biochem. Cell Biol. 35: 769-773.

Costerousse O, Allegrini J, Lopez M and Alhenc-Gelas F (1993). Angiotensin I-converting enzyme in human circulating mononuclear cells: genetic polymorphism of expression in T-lymphocytes. Biochem. J. 290: 33-40.

Danser AH, Schalekamp MA, Bax WA, van den Brink AM, et al. (1995). Angiotensin-converting enzyme in the human heart. Effect of the deletion/insertion polymorphism. Circulation 92: 1387-1388.

DerSimonian R and Laird N (1986). Meta-analysis in clinical trials. Control Clin. Trials 7: 177-188.

Egger M, Davey SG, Schneider M and Minder C (1997a). Bias in meta-analysis detected by a simple, graphical test. BMJ 315: 629-634.

Egger M, Smith GD and Phillips AN (1997b). Meta-analysis: principles and procedures. BMJ 315: 1533-1537.

Fatini C, Gensini F, Sticchi E, Battaglini B, et al. (2002). High prevalence of polymorphisms of angiotensin-converting enzyme (I/D) and endothelial nitric oxide synthase (Glu298Asp) in patients with systemic sclerosis. Am. J. Med. 112: 540-544.

Gabrielli A, Avvedimento EV and Krieg T (2009). Scleroderma. N. Engl. J. Med. 360: 1989-2003.

Guiducci S, Fatini C, Rogai V, Cinelli M, et al. (2006). Angiotensin-converting enzyme in systemic sclerosis: from endothelial injury to a genetic polymorphism. Ann. New York Acad. Sci. 1069: 10-19.

Higgins JP and Thompson SG (2002). Quantifying heterogeneity in a meta-analysis. Stat. Med. 21: 1539-1558.

Joung CI, Park YW, Kim SK, Uhm WS, et al. (2006). Angiotensin-converting enzyme gene insertion/deletion polymorphism in Korean patients with systemic sclerosis. J. Kor. Med. Sci. 21: 329-332.

Kranzhofer R, Schmidt J, Pfeiffer CA, Hagl S, et al. (1999). Angiotensin induces inflammatory activation of human vascular smooth muscle cells. Arterioscler. Thromb. Vasc. Biol. 19: 1623-1629.

Lee YH, Witte T, Momot T, Schmidt RE, et al. (2005). The mannose-binding lectin gene polymorphisms and systemic lupus erythematosus: two case-control studies and a meta-analysis. Arthritis Rheum. 52: 3966-3974.

Lee YH, Harley JB and Nath SK (2006). Meta-analysis of TNF-alpha promoter -308 A/G polymorphism and SLE susceptibility. Eur. J. Hum. Genet. 14: 364-371.

Lee YH, Choi SJ, Ji JD and Song GG (2012). Associations between the angiotensin-converting enzyme insertion/deletion polymorphism and susceptibility to vasculitis: a meta-analysis. J. Renin. Angiotensin. Aldosterone. Syst. 13: 196-201.

Li Y (2012). Angiotensin-converting enzyme gene insertion/deletion polymorphism and essential hypertension in the Chinese population: a meta-analysis including 21,058 participants. Intern. Med. J. 42: 439-444.

Marchesi C, Paradis P and Schiffrin EL (2008). Role of the renin-angiotensin system in vascular inflammation. Trends 
Pharmacol. Sci. 29: 367-374.

Nataraj C, Oliverio MI, Mannon RB, Mannon PJ, et al. (1999). Angiotensin II regulates cellular immune responses through a calcineurin-dependent pathway. J. Clin. Invest. 104: 1693-1701.

Nath SK, Harley JB and Lee YH (2005). Polymorphisms of complement receptor 1 and interleukin-10 genes and systemic lupus erythematosus: a meta-analysis. Hum. Genet. 118: 225-234.

Rigat B, Hubert C, Alhenc-Gelas F, Cambien F, et al. (1990). An insertion/deletion polymorphism in the angiotensin I-converting enzyme gene accounting for half the variance of serum enzyme levels. J. Clin. Invest. 86: 1343-1346.

Samani NJ, Thompson JR, O'Toole L, Channer K, et al. (1996). A meta-analysis of the association of the deletion allele of the angiotensin-converting enzyme gene with myocardial infarction. Circulation 94: 708-712.

Steen VD, Costantino JP, Shapiro AP and Medsger TA Jr (1990). Outcome of renal crisis in systemic sclerosis: relation to availability of angiotensin converting enzyme (ACE) inhibitors. Ann. Intern. Med. 113: 352-357.

Tao HM, Shao B and Chen GZ (2009). Meta-analysis of the ACE gene polymorphism in cerebral infarction. Can. J. Neurol. Sci. 36: 20-25.

Wipff J, Gallier G, Dieude P, Avouac J, et al. (2009). Angiotensin-converting enzyme gene does not contribute to genetic susceptibility to systemic sclerosis in European Caucasians. J. Rheumatol. 36: 337-340. 